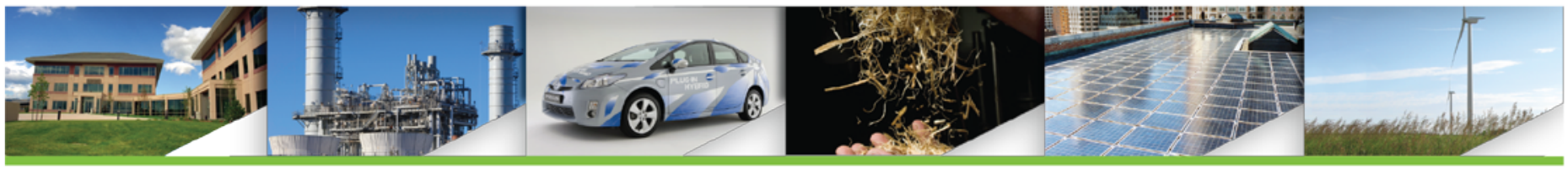

\title{
Accelerating Clean Energy Commercialization: A Strategic Partnership Approach
}

Richard Adams

Innovation and Entrepreneurship Center

National Renewable Energy Laboratory

Jacquelyn Pless and Douglas J. Arent

Joint Institute for Strategic Energy Analysis

Ken Locklin

Impax Asset Management Group

The Joint Institute for Strategic Energy Analysis is operated by the Alliance for Sustainable Energy, LLC, on behalf of the U.S. Department of Energy's National Renewable Energy Laboratory, the University of Colorado-Boulder, the Colorado School of Mines, the Colorado State University, the Massachusetts Institute of Technology, and Stanford University.

Technical Report

NREL/TP-6A60-65374

April 2016

Contract No. DE-AC36-08GO28308 


\section{Accelerating Clean Energy Commercialization: A Strategic Partnership Approach}

\section{Richard Adams}

Innovation and Entrepreneurship Center

National Renewable Energy Laboratory

Jacquelyn Pless and Douglas J. Arent

Joint Institute for Strategic Energy Analysis

Ken Locklin

Impax Asset Management Group

Prepared under Task Nos. 6A60.4000; 6A43.2012

The Joint Institute for Strategic Energy Analysis is operated by the Alliance for Sustainable Energy, LLC, on behalf of the U.S. Department of Energy's National Renewable Energy Laboratory, the University of Colorado-Boulder, the Colorado School of Mines, the Colorado State University, the Massachusetts Institute of Technology, and Stanford University.

JISEA $^{\circledR}$ and all JISEA-based marks are trademarks or registered trademarks of the Alliance for Sustainable Energy, LLC.

The Joint Institute for Strategic Energy Analysis 15013 Denver West Parkway Golden, CO 80401 303-275-3000 • www.jisea.org
Technical Report

NREL/TP-6A60-65374

April 2016

Contract No. DE-AC36-08GO28308 


\section{NOTICE}

This report was prepared as an account of work sponsored by an agency of the United States government. Neither the United States government nor any agency thereof, nor any of their employees, makes any warranty, express or implied, or assumes any legal liability or responsibility for the accuracy, completeness, or usefulness of any information, apparatus, product, or process disclosed, or represents that its use would not infringe privately owned rights. Reference herein to any specific commercial product, process, or service by trade name, trademark, manufacturer, or otherwise does not necessarily constitute or imply its endorsement, recommendation, or favoring by the United States government or any agency thereof. The views and opinions of authors expressed herein do not necessarily state or reflect those of the United States government or any agency thereof.

Available electronically at SciTech Connect: http:/www.osti.gov/scitech

Available for a processing fee to U.S. Department of Energy and its contractors, in paper, from:

U.S. Department of Energy

Office of Scientific and Technical Information

P.O. Box 62

Oak Ridge, TN 37831-0062

OSTI http://www.osti.gov

Phone: 865.576.8401

Fax: 865.576.5728

Email: reports@osti.gov

Available for sale to the public, in paper, from:

U.S. Department of Commerce

National Technical Information Service

5301 Shawnee Road

Alexandria, VA 22312

NTIS http://www.ntis.gov

Phone: 800.553 .6847 or 703.605 .6000

Fax: 703.605.6900

Email: orders@ntis.gov 


\section{Abstract}

Technology development in the clean energy and broader clean tech space has proven to be challenging. Long-standing methods for advancing clean energy technologies from science to commercialization are best known for relatively slow, linear progression through research and development, demonstration, and deployment (RDD\&D); and characterized by well-known valleys of death for financing. Investment returns expected by traditional venture capital investors have been difficult to achieve, particularly for hardware-centric innovations, and companies that are subject to project finance risks. Commercialization support from incubators and accelerators has helped address these challenges by offering more support services to start-ups; however, more effort is needed to fulfil the desired clean energy future.

The emergence of new strategic investors and partners in recent years has opened up innovative opportunities for clean tech entrepreneurs, and novel commercialization models are emerging that involve new alliances among clean energy companies, RDD\&D, support systems, and strategic customers. For instance, Wells Fargo and Company (WFC) and the National Renewable Energy Laboratory (NREL) have launched a new technology incubator that supports faster commercialization through a focus on technology development. The incubator combines strategic financing, technology and technical assistance, strategic customer site validation, and ongoing financial support. 


\section{Table of Contents}

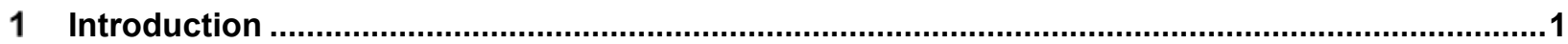

2 Technological and Commercialization Valleys of Death .............................................................

3 New Pathways for Accelerating Clean Energy Commercialization .................................................6

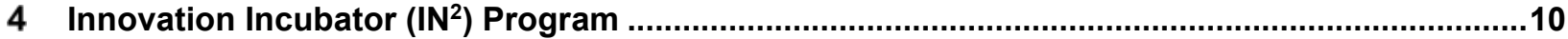

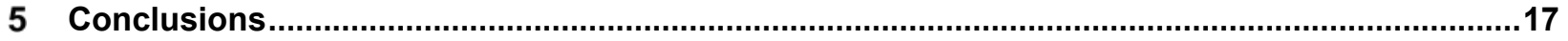

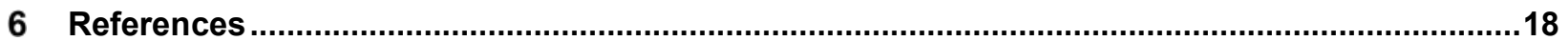




\section{Introduction}

New clean energy technologies are a growing component of energy portfolios around the world. Their growth takes place against the backdrop of an increasingly complex energy landscape characterized by:

- Changing local and system priorities

- Reliability and resiliency concerns

- Energy access inequality issues

- Quality of life requirements

- Impacts on water and food security

- Aging infrastructure in more developed markets

- Economic and energy security challenges.

In an attempt to increase the success rate for start-up companies, which often introduce new clean energy technologies into the market, innovative approaches to technology commercialization are emerging. Initial support in the form of "incubators" provided core business services such as office space and back office infrastructure, along with access to experienced entrepreneurs and business advisors. The incubator approach most often did not provide the companies with help for fundraising, a crucial challenge for the start-up enterprise. To reduce this impediment, a new variant called an "accelerator" emerged that also included equity investment for select companies (Malek et al. 2014). This model proved most successful for companies that have minimal capital costs and the potential for rapid sales cycles (software and social media plays are examples).

However, hardware-intensive firms face both early and later stage funding challengesthe so-called valleys of death, during which the funding requirements of the developing enterprise are not well matched by available financing resources. The valleys of death have proven especially challenging for energy-related companies that sell into highly capital intensive, project-based markets or to regulated customers that may have a slower rate of new technology adoption. Supporters of new clean energy development hypothesized that commercialization of hardware-centric energy solutions could be accelerated with "enabling ecosystems"-more "organic" arrangements combining strong technical support, business/product verification, flexible financing, and commercial validation. In aggregate, these components are expected to shorten technology development cycles.

This document describes where the sector has been in terms of investment trends and technology commercialization challenges, initial efforts to solve these challenges, and new emerging models designed to bridge resource and finance gaps in the form of strategic industry partnerships. It also explores a number of novel strategies that are operational in the market today for accelerating clean energy commercialization through innovative financing and technology support. 


\section{Technological and Commercialization Valleys of Death}

The modernization of our energy systems requires the clean energy sector to address a multitude of critical challenges. As part of this mix, two key financing gaps impede energy innovation. These gaps are widely recognized as the (early-stage) technological and (later-stage) commercialization valleys of death (see Figure 1). While obtaining financing can be an obstacle for most innovative technologies, the challenge is particularly acute in the energy sector (Jenkins and Mansur 2011) due to the inherent risks that exist in the commercialization of clean energy technologies. The gaps have appeared both between the angel and venture capital (VC) investment stages and within the growth stage leading to development and full-scale commercialization. Investors today face a decision space in which innovative models are needed to reassess risk and profitability (Heap et al. 2013). Decreased funding across all investment sectorsincluding angels, VCs, growth equity, and debt providers - has led to increased gaps in support for technology innovation.

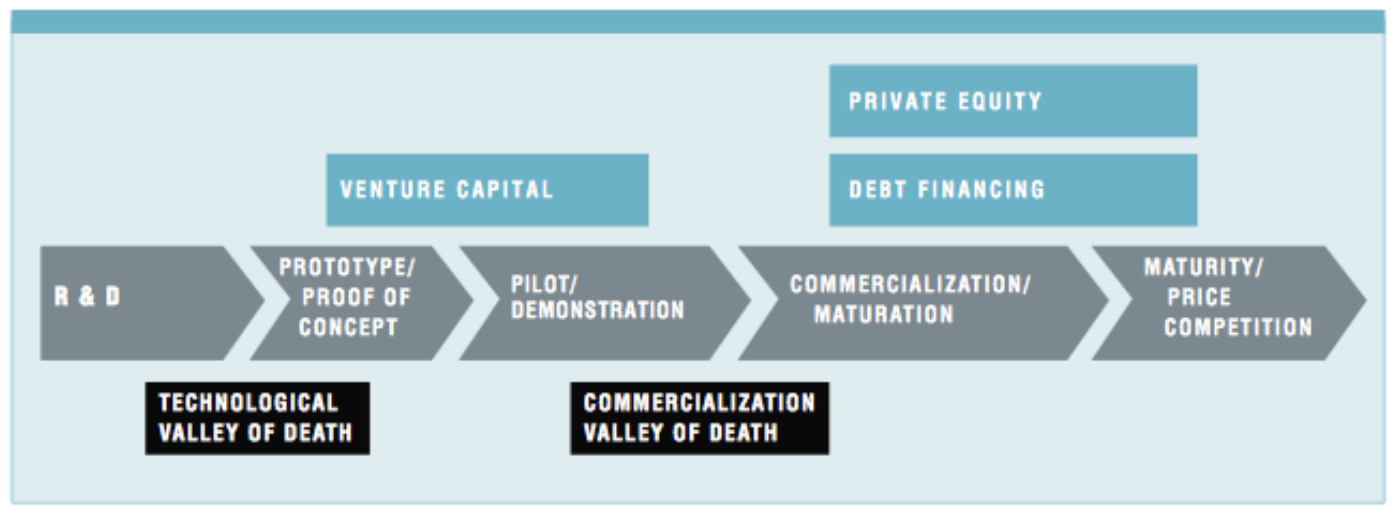

Figure 1. The energy innovation cycle and the clean energy valleys of death

Source: Jenkins and Mansur 2011

\section{Technology Valley of Death}

The technological valley of death occurs early in the innovation and development process, as entrepreneurs conduct research and require capital to develop, test, and refine technologies. Entrepreneurs demonstrate product and market viability to private funders in this phase. This stage is characterized by high technical, market, and management risks as well as long development horizons.

Higher-risk venture capital has typically aided early-stage businesses, with VC investment in clean tech start-ups rising from 2006 to 2009. However, VC investment in renewable energy declined significantly between 2010 and 2013 (see Figure 2), which created a critical gap in finance and expertise for the commercialization of new technologies. The global economic downturn of 2008-2009 reinforced inherent barriers to clean energy technology investment, with heightened concern about time-to-return, capital intensity, time-to-exit, and policy risks (Rai et al. 2015). Global VC and private 
equity (PE) investment in renewable energy declined 30\% to $\$ 4$ billion in 2012 relative to 2011, its lowest level since 2005 (UNEP/BNEF 2013). Reductions in available PE expansion capital accounted for $75 \%$ of this decline, while most of the remainder was due to reductions in early-stage VC investment (down $\$ 300$ million to $\$ 530$ million). Specifically, first-time funding in renewable energy decreased as well, falling $95 \%$ to $\$ 3$ million in Q2 2013 relative to Q2 of 2012 (Heap et al. 2013).

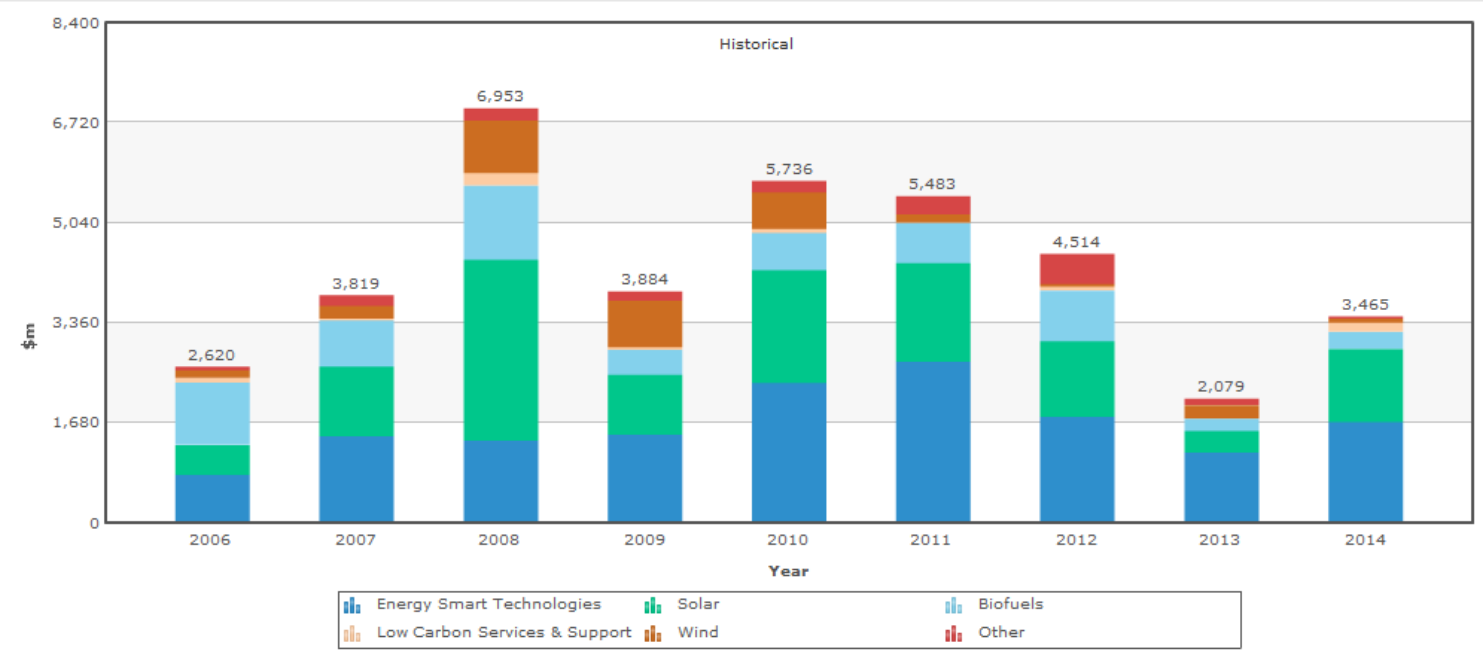

Figure 2. U.S. VC/PE new investment in renewable energy by sector, 2006-2014, \$bn

Source: Bloomberg New Energy Finance 2015

Despite a bounce back in investment in 2014, these trends in private capital have led to a scarcity of funds for entrepreneurs seeking to commercialize high-risk, high-reward technologies in the clean energy market. Traditional VC models based upon 10-year closed-end funds often cannot handle the long time horizons required to scale early-stage energy technologies and achieve an exit. Other private equity investors may accept longer time horizons but can be uncomfortable with the technology risk associated with these early-stage companies. VC firms mostly expect a shorter time frame for exit (about 3-5 years). Longer investment payoff periods for advanced energy technologies can be discouraging for investors today. At the other end of the investor spectrum, angel investors who sometimes tolerate higher risk projects find the level of capital to fund projects across the technological valley of death is beyond their means (Jenkins and Mansur 2011).

Upstream commercialization support for clean energy innovations is lacking, largely due to a shift by VC firms to more profitable downstream ventures (Murphy et al. 2014). Where these firms might previously have funded an earlier venture investment round, many have now opted to move down the continuum to later stage investments with lower perceived risk, lower capital requirements, and shorter return horizons (Rosen 2013).

\section{Commercialization Valley of Death}

For clean energy start-ups, a second challenge emerges with the commercialization valley of death, which exists between the demonstration and commercialization phases of 
development. This valley of death reflects the gaps between the traditional role of VCs and those of other project financiers and later stage debt/equity investors (Jenkins and Mansur 2011). Because project financiers typically seek to finance commercial-scale projects only for proven technologies with less risk, the commercialization valley of death is increasingly becoming an insurmountable barrier. This is particularly true for technologies that have successfully completed the proof-of-concept stage but still require large capital investments to demonstrate design and manufacturing capabilities for fullscale commercialization. The capital requirements for commercializing these technologies are beyond the risk tolerance and timelines of most debt and equity market participants (BNEF 2010). This mismatch can prevent advanced energy technologies, which are too capital-intensive for VCs yet too risky for traditional project financiers, from reaching scale production.

The combined effect of these financing challenges is a major gap in the availability of private capital for early-stage energy technology commercialization that leaves many small clean energy businesses unable to scale (Murphy et al. 2014). The valleys of death create critical gaps in the finance and expertise pathways of technology development and commercialization, limiting the likelihood of next generation technology innovations ever reaching the marketplace. Many advanced energy technologies are unable to transition from earlier stage VC equity financing to traditional later stage debt-based funding.

As start-ups continue to face the challenges of accessing resources for the technology commercialization process, new kinds of resource partnerships are needed to help close these gaps. Today's energy decision space requires innovative financing and investment models to appropriately reassess risk and profitability (Heap et al. 2013).

One potential opportunity for bridging resources and eliminating these investment gaps is the pursuit of large strategic industry partnerships (SIPs). With significant resource bases including marketing, capital, technical, manufacturing, and supply chain expertise, SIPs can provide more industry stability (see Figure 3 ). SIPs can often provide more patient capital than other sources and vertically integrate needed resources.

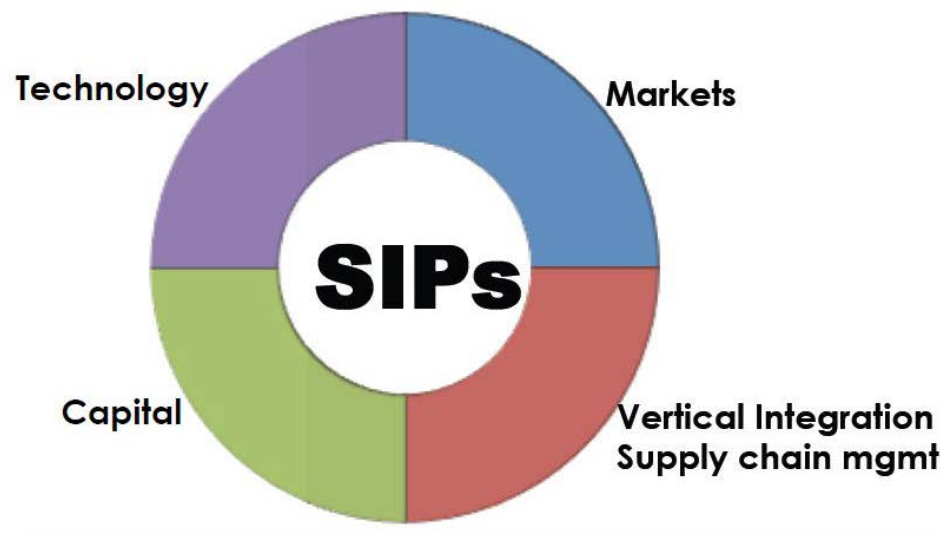

Figure 3. Strategic industry partnerships (SIPs) can provide integrated expertise and access to many resources.

Source: Murphy et al. 2014 
The emergence of strategic investors and strategic partners in recent years has opened up new opportunities for clean energy entrepreneurs. Novel models for commercialization acceleration are emerging involving new alliances among clean energy companies, RDD\&D support systems, and strategic customers. Firms from a variety of industries including real estate, finance, manufacturing, and transport are showing a growing interest in clean energy business opportunities. These firms can offer a broad spectrum of resources that span a range of upstream and downstream needs. At the same time, in order for strategic partnerships to be successful, many SIPs will require good visibility of potential future revenue streams with a transparent path toward sustained profitability.

It is the intersection of innovative policy, venture capital, and strategic corporate investment that facilitates sector-wide learning, with each component contributing critically to the advancement of clean energy technologies (Rai et al. 2015). 


\section{New Pathways for Accelerating Clean Energy Commercialization}

A variety of new efforts aimed toward increasing the prospects for successful commercialization of advanced energy technologies have emerged in recent years, several of which were developed by U.S. Department of Energy (DOE) national laboratories or leading research universities. These program designs were informed by analysis of the challenges that start-ups and other private firms currently face as they advance toward commercialization. These new approaches provide the private sector with access to the technological leadership and expertise that the DOE national laboratories and leading research institutions can provide. This section summarizes a few of these programs.

\section{Cyclotron Road}

Launched in 2014, Cyclotron Road is a novel approach to bridging the seemingly daunting science-to-product gap that many advanced technology companies face. Anchored by Lawrence Berkeley National Laboratory (LBNL), the program aims to advance progress in clean energy "hard technologies" (those involving physical devices), which are necessary for building sustainable energy systems. The program entails recruiting top technical talent with strong entrepreneurial drive, immersing the recruits in a supported laboratory environment, and linking them with technical and commercial mentors.

Cyclotron Road focuses on:

- Recruiting the best and "most driven" advanced energy technology innovators

- Focusing on potential innovations that are believed to be both commercially relevant and scalable, leading to market impact potential

- Leveraging the R\&D support offered by LBNL and other national labs

- Assisting the recruited technology leaders with top flight technical and commercial mentors, training, and seed funding

- Connecting recruits with appropriately matched commercial partners.

The 20 entrepreneurs in Cyclotron Road's first "class" of recruits have already demonstrated significant acceleration of technological understanding and competency in their initial months in the program, according to program managers (N. Schuetz and S. Lounis, pers. comm.).

\section{PRIME}

PRIME is a new 501(c)(3) organization seeking to unite leading philanthropies with opportunities to invest in what its leadership believes to be "mission-critical" technological innovations supporting the well-being of the planet. PRIME assists donors with its internal tools and structures to facilitate rapid decision-making and solution development while serving as a clearinghouse of pre-commercial resources for 
entrepreneurs with high impact ideas in its fields of concentration (S. Pfeiffer, pers. comm.).

While PRIME will consider a range of programmatic initiatives over time, its initial focus is on climate change mitigation. An extensive team of "fellows" and an associated "Brain Trust" work together to identify high priority initiatives. The PRIME staff and investment committee evaluate initiatives prior to offering the technological solutions viewed as having the greatest potential to the member philanthropies to consider for investment.

Selected opportunities must be judged as high impact, potentially attractive to later rounds of funding, and positioned so that the PRIME support will not be likely to crowd out traditional investors. PRIME aims to help its support recipients bridge both the technological and commercialization valleys of death largely through non-traditional financing channels.

\section{NREL Commercialization Assistance Program}

The NREL Commercialization Assistance Program (NCAP) is another effort by a DOE national lab aimed at assisting entrepreneurs in overcoming the technical barriers that they may face in moving advanced energy technologies to market. The program assists renewable energy and energy efficiency start-ups (small and emerging businesses with fewer than 500 employees) by providing free assistance or information to solve a specific technical challenge (NREL 2015). Under the program, NREL provides up to 40 hours of free assistance, such as short-term access to technical expertise and facilities, to help the recipient solve a technical issue and move along the commercialization path. Examples of assistance include:

- Testing and measuring systems or components

- Analytical testing of materials

- Insights on existing or emerging technologies

- Assistance addressing technological performance and market analysis

- Assistance addressing general technology problems.

\section{DOE Small Business Voucher Pilot program}

Like NCAP, DOE's Small Business Vouchers (SBV) pilot program aims to help clean energy small business managers and entrepreneurs surmount the technical challenges inherent in bringing innovative technologies to market. SBV has an even broader reach than NCAP. Supported by $\$ 20$ million of DOE funding, the program is able to provide deeper and longer technical assistance to specific projects.

The SBV program aims to serve more than 100 small businesses by providing vouchers valued from $\$ 50 \mathrm{~K}$ to $\$ 300 \mathrm{~K}$ that can be exchanged for access to the expertise and tools of any of five DOE national laboratories: Oak Ridge National Laboratory, National Renewable Energy Laboratory, Lawrence Berkeley National Laboratory, Sandia National Laboratories, and Pacific Northwest National Laboratory (Karen Henry, pers. comm.). The tailored technical support is designed to help start-ups test, validate, and roll out new 
products in the clean energy sector. Recipients are required to provide support equal to $20 \%$ of the lab's assistance through matching funds or in-kind services.

\section{CalCharge (UC-Davis Energy Efficiency Center)}

CalCharge is a 501(c)(3) entity sponsored by the California Clean Energy Fund (CalCEF) that brings together a broad coalition of leading organizations committed to advancing energy efficiency and aligns them with the Energy Efficiency Center's world-class graduate faculty and sector-focused students. The center's mission is to accelerate the development and commercialization of energy efficiency technologies and solutions, while also training future leaders in the sector.

The CalCharge research is primarily focused on energy efficiency in lighting and heating, air-conditioning, and ventilation systems, but it also addresses transportation issues, primarily in the hybrid and electric vehicle sectors. CalCharge seeks to develop products particularly suitable for the United States and other developed markets; however, it is also open to products that could be applied in developing countries. The center relies upon a strong public-private partnership and active collaboration among industry, government, and university partners. Its programs combine applied research and close collaboration with the major California utility and corporate participants who make up its donor base. These collaborators, working together closely within the flexible not-forprofit framework, enable CalCharge to move new technologies from the lab to field in an accelerated fashion (St. John 2014).

\section{DOE Lab-Corps Program}

Lab-Corps is an entrepreneurial training program for laboratory researchers with a goal of increasing the number of successfully commercialized lab-developed technologies by giving the researchers access to direct market feedback. The Lab-Corps curriculum utilizes an evidence-based learning process that places the team in the role of entrepreneur and guides them through the development of a viable Business Model Canvas for their technology. At the core of the curriculum is the customer discovery process that challenges teams to conduct 75-100 customer interviews with the goals of gaining a better understanding of the market needs that relate to their technology and learning what problems need to be solved. Lab-Corps successfully launched with a cohort of 14 teams in late 2015 and is preparing to continue with a second cohort of 14 teams in spring of 2016.

\section{State-Based Clean Energy Funds}

Over the last decade, a number of states have launched locally focused clean energy investment and/or enterprise development funds. California, Colorado, Connecticut, Massachusetts, New Jersey, New York, Oregon, and others have utilized varying combinations of ratepayer, state, and federal resources to provide formal business development or investment support for local clean energy start-ups. Some, such as Colorado's Advanced Industries Accelerator Grants program, have been structured along traditional grant-based funding designs and aimed at providing early "accelerator" 
assistance to state-based startups. ${ }^{1}$ Others, such as the California Clean Energy Fund and the Massachusetts Green Energy Fund, were structured as traditional limited partnership investment funds or "fund of funds." These vehicles involve a combination of commitments from private investors alongside public resources and seek commercial venture capital rates of return.

The support funds range in size from pilot programs of less than \$1 million to fully staffed commercial scale investment operations with tens of millions of dollars in capitalization. These larger funds can participate in individual ventures that can mobilize over $\$ 100$ million of investment capital. Regardless of their size or structure, both fund managers and recipients have cited the successful launch of numerous clean energy startups as evidence of their success.

\footnotetext{
${ }^{1}$ The Colorado program supports a number of high priority industries, including clean energy.
} 


\section{Innovation Incubator (IN $\left.{ }^{2}\right)$ Program}

To further understand the strategic industry partnership models that are emerging to address challenges that entrepreneurs face along the innovation and commercialization pathway, this section explores one example in greater detail.

NREL and the foundation arm of U.S. financial services leader Wells Fargo \& Company (WFC) created the Innovation Incubator $\left(\mathrm{IN}^{2}\right)$ program to more comprehensively accelerate the commercialization of advanced energy and sustainability solutions. $\mathrm{IN}^{2}$ departs from other recent efforts in several ways, including:

- $\mathrm{IN}^{2}$ is specifically designed to integrate early-stage grant financing with technical assistance to accelerate commercialization in a comprehensive manner. $\mathrm{IN}^{2}$ technical and financial interventions are carefully tailored to support a start-up enterprise at critical stages.

- $\mathrm{IN}^{2}$ is structured to support early-stage, middle-stage, and later stage companies, enabling them to potentially clear both the technological and commercialization valleys of death.

- $\quad \mathrm{IN}^{2}$ assistance can be sustained beyond early-stage technology development and can support accelerated enterprise growth over time.

WFC is a global financial services organization with $\$ 1.7$ trillion in assets. Founded in 1852 and headquartered in San Francisco, Wells Fargo provides banking, insurance, investments, mortgage, and consumer and commercial finance through more than 8,700 U.S. locations. WFC has offices in 36 countries, a staff of over 265,000, and is a Fortune 50 company.

As part of the bank's environmental commitment to accelerate the transition to a greener economy, WFC is supporting clean technology and renewable energy sources through lending and investment, both within their operations and through their strategic philanthropy programs. Their commitment includes a goal to provide $\$ 100$ million in environmental grants by 2020. In 2014 WFC launched a new enterprise-wide strategic philanthropy pilot program, the Wells Fargo Innovation Incubator- $\mathrm{IN}^{2}$. This program consolidates WFC's environmental commitment by leveraging its extensive physical, financial, and commercial footprint. $\mathrm{IN}^{2}$ utilizes the firm's acknowledged environmental finance expertise and deepens its relationships with key community partners to support emerging clean technologies that are critical to building a more sustainable future.

The $\mathrm{IN}^{2}$ platform is funded by the Wells Fargo Foundation and co-administered by NREL - the only DOE laboratory focused solely on the research, development, and commercialization of renewable energy and energy efficiency technologies. The program is funded by a 5-year, \$10 million grant from the Wells Fargo Foundation to the Alliance for Sustainable Energy LLC - the operator of NREL. The program incorporates participation by Wells Fargo and by other external industry stakeholders including leading accelerators and industry labs, research institutes, and universities. 
The goals of the program include building greater collaboration among WFC and clean energy stakeholders, and leveraging WFC's assets and expertise to advance early stage technology companies, while driving economic development across the communities Wells Fargo serves.

To source applicants for the invitation-only program, $\mathrm{IN}^{2}$ has identified nearly 30 leading accelerators, universities, and research institutes across the United States to participate as channel partners (Table 1). These partners identify and refer clean technology companies from their portfolio to apply to the program.

Table 1. WFC Channel Partners

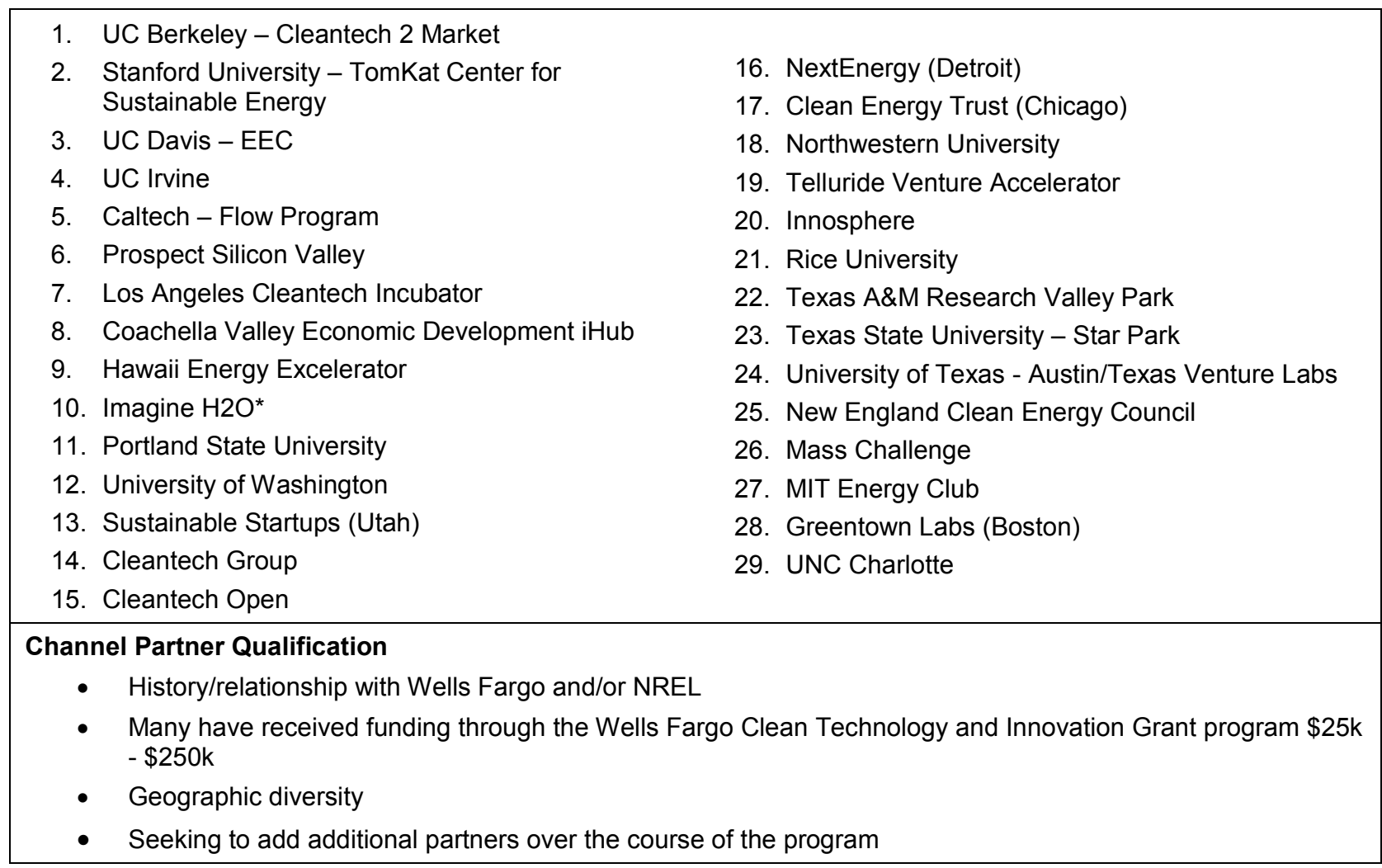

Initially, efforts focus on supporting early stage companies that have technology solutions for the commercial built environment, recognizing that buildings consume over $40 \%$ of annual energy usage in the United States (EIA 2015). The following are themes and examples of technologies that are eligible for support:

- Energy efficiency

- Net zero-energy

- Water efficiency

- Indoor air quality

- Waste reduction 
- Materials efficiency

- Operations optimization

- Lighting

- Sensors and controls

- Space heating and cooling

- Windows, skylights, doors

- Energy modeling

- Plug loads.

Following a competitive review process, early-stage companies are invited into the $\mathrm{IN}^{2}$ program, where they will receive grant funding or non-dilutive capital ranging from $\$ 50 \mathrm{~K}$ to $\$ 250 \mathrm{~K}$ for primarily technical assistance as well as business-related needs. Round 1 of $\mathrm{IN}^{2}$ awarded four startup companies into the program in early 2015, and Round 2 awarded six new companies into the program in December 2015.

Round 1 companies include:

- Energy Storage Systems (all-iron redox flow battery)

- LiquidCool Solutions (liquid cooling technology for computer and electronics)

- VG SmartGlass (polarizing film based window technology)

- Whisker Labs (peel-and-stick submetering sensor)

Round 2 companies include:

- 7AC Technologies (liquid desiccant air conditioning)

- Go Electric Inc. (microgrid/uninterruptible power system)

- Heliotrope Technologies (electrochromic smart window technology)

- NETenergy (thermal energy storage air conditioning system)

- Polyceed, Inc. (dynamic smart window technology)

- ThermoLift Inc. (natural gas-driven heat pump and air conditioner)

Participating companies will spend a period of time incubating their technologies at NREL, where they will be provided access to researchers and testing facilities to help them design and meet key validation milestones on their paths to commercialization. Ultimately, near commercially ready $\mathrm{IN}^{2}$ participants may receive an opportunity to beta test their innovative products within the Wells Fargo network of offices and facilities, which includes nearly 100 million square feet of real estate globally. The opportunity to demonstrate technologies in this real-world environment is a critical step to de-risking the technology and go-to-market strategy. Awardee companies will also have access to relevant Wells Fargo financial services, products, information, and mentorship. 
The $\mathrm{IN}^{2}$ platform supports various stages of emerging clean technologies that are categorized into three tiers: Bench Scale, Prototype, and Commercially Ready (Table 2). The goal is to help each tier of companies meet critical milestones to assist them in advancing to the next stage of development and ultimately assist them in achieving successful commercialization. However, there is no guarantee that every technology that comes into the program will successfully transition to the commercial marketplace. Even in the cases where this goal is not achieved, significant value can be added through the $\mathrm{IN}^{2}$ process to help companies refine their technologies and potentially pivot to alternative approaches or market segments, if necessary.

Table 2. IN's Three Tiers of Emerging Clean Energy Technologies

\begin{tabular}{|c|c|c|c|c|}
\hline & Program & $\begin{array}{l}\text { Technology } \\
\text { Status }\end{array}$ & $\begin{array}{l}\text { Value } \\
\text { Proposition }\end{array}$ & Funding \\
\hline \multirow{3}{*}{ 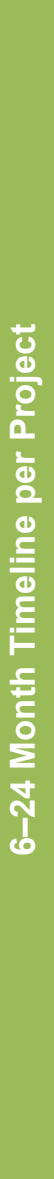 } & $\begin{array}{l}\text { Tier I: Bench } \\
\text { Scale }\end{array}$ & $\begin{array}{l}\text { - Conceptual state } \\
\text { with physical } \\
\text { proof that the } \\
\text { concept may } \\
\text { work } \\
\text { - Development } \\
\text { plans for } \\
\text { prototyping and } \\
\text { testing } \\
\text { - 3-5 years to } \\
\text { market }\end{array}$ & $\begin{array}{l}\text { - Access to world- } \\
\text { class researchers } \\
\text { and facilities } \\
\text { - Further } \\
\text { technology } \\
\text { development }\end{array}$ & \multirow{3}{*}{$\begin{array}{l}\text { Funding levels } \\
\text { are anticipated to } \\
\text { be between } \\
\$ 50 \mathrm{~K} \text { and } \$ 250 \mathrm{~K} \text {, } \\
\text { dependent on } \\
\text { project needs }\end{array}$} \\
\hline & Tier II: Prototype & $\begin{array}{l}\text { - Prototype } \\
\text { available for } \\
\text { testing and } \\
\text { validation } \\
\text { - Plans available } \\
\text { for development } \\
\text { of final product } \\
\text { - Less than } 2 \text { years } \\
\text { to market }\end{array}$ & $\begin{array}{l}\text { - Access to world- } \\
\text { class researchers } \\
\text { and facilities } \\
\text { - Testing and } \\
\text { validation of } \\
\text { prototype }\end{array}$ & \\
\hline & $\begin{array}{l}\text { Tier III: } \\
\text { Commercially } \\
\text { ready }\end{array}$ & $\begin{array}{l}\text { - Production } \\
\text { models available } \\
\text { in limited quantity } \\
\text { - Less than } 18 \\
\text { months to market }\end{array}$ & $\begin{array}{l}\text { - Access to world- } \\
\text { class researchers } \\
\text { and facilities } \\
\text { - Potential for } \\
\text { deployment within } \\
\text { WF footprint } \\
\text { - Evaluation and } \\
\text { support of } \\
\text { deployment plan }\end{array}$ & \\
\hline
\end{tabular}

The needs of each company admitted into the program differ based on their stage of development, with Tier 1 and Tier 2 technologies seeking assistance to transition from basic R\&D to developing a prototype and subsequently validating performance of that prototype. Assistance for these companies is targeted at overcoming the Technology valley of death. Tier 3 companies, with generally commercially ready solutions, often require validation in real-world settings in order to combat the commercialization valley of 
death and achieve funding to scale. The potential to beta test at a Wells Fargo or another partner location at this stage presents a critical opportunity to advancing a technology's commercialization.

The complete $\mathrm{IN}^{2}$ program cycle includes: i) Evaluation and selection by 3 stages of review boards, ii) technical projects lasting 6-18 months, and iii) beta testing for applicable Tier 3 technologies. However, in cases where WFC believes that a tested product has particular merit, either for WFC application or in the broader market, a range of other potential interactions with WFC entities are possible. Depending on WFC's circumstances and commercial interests, these could include any or all of the following further interventions:

- Potential for WFC to enter into a formal commercial arrangement with an $I N^{2}$ awardee to purchase successful products for installation in the WFC real estate portfolio. Installed technologies that are both technically successful and of commercial interest to the WFC buildings management team could be purchased from the start-up awardee.

- Commercial bank financing and other finance services. WFC manages one of the largest U.S. commercial banking networks. It has a wide range of services to offer to commercialization-ready $\mathrm{IN}^{2}$ awardees, potentially including the financing to the end-purchasers of selected $\mathrm{IN}^{2}$ technologies. Securing such third-party financing for any capital intensive technology is a critical challenge typically facing start-up manufacturers.

- Introduction of successful products to WFC real-estate partners in buildings it does not wholly own and/or Wells Fargo customers. In relevant instances, WFC could further assist the $\mathrm{IN}^{2}$ awardees by sharing WFC's insights on the value of successfully vetted technologies with partners across the real estate joint ventures in which WFC participates, and/or potentially with other WFC customers.

- Assistance in fundraising via introductions to potentially interested WFC investor clients. The Wells Fargo Foundation team can work with their WFC Wealth Management colleagues to introduce awardees to potential investors interested in expanding their exposure to advanced energy technologies.

The WFC team has been effective in coordinating interest in these potential technology companies due to the time and dedication placed on building strong connections across its own large organization nationwide in advance of the launch of the initial $\mathrm{IN}^{2}$ technology solicitation. The principal units within WFC supporting $\mathrm{IN}^{2}$ include:

- The Wells Fargo Foundation

- WFC Commercial Real Estate

- WFC Environmental Finance

- Corporate Properties Group

- Government Relations 
- Wells Fargo Legal

- Community Lending and Investing

- Supply Chain Management/Supplier Diversity

- Technology and Operations Group

- Global Commercial Cleantech Banking Group

- Environmental Affairs.

The NREL team has similarly developed a multi-program partnership across the lab. NREL's Innovation and Entrepreneurship Center has led the design and development of the $\mathrm{IN}^{2}$ initiative internally. The Innovation and Entrepreneurship Center has engaged a number of team members able to provide technology assessments as well as measurement and verifications capabilities to track the progress of $\mathrm{IN}^{2}$ winners. These include:

- The Building and Thermal Systems Center

- Strategic Energy Analysis Center

- Energy Systems Integration Program

- Joint Institute for Strategic Energy Analysis.

The $\mathrm{IN}^{2}$ program design grew out of recognition on the part of WFC that it needed to create a systematic, continuum-wide approach to boosting clean energy technology adoption. The WFC and NREL teams spent considerable time exploring the complexity of technology commercialization issues. The model is interesting in part because it is funded by a commercial financial institution rather than a high-tech product manufacturer, which could be expected to be more versed in designing, developing, and deploying novel commercial products.

WFC's decision to forge an early alliance with a technology development leader such as NREL underscores WFC's understanding of the complexities clean energy startups face. The $\mathrm{IN}^{2}$ model is notable in part because of the range of its planned commercialization efforts, the continuity of its program services, and its interesting mix of "soft" grant resources and "hard" commercial financing and operational funding support. Prior research has established that start-ups typically benefit from access to a full ecosystem of innovation support. Providing assistance across the continuum of services potentially encompassed by $\mathrm{IN}^{2}$ could significantly enhance a start-up firm's prospects for success and shorten the time between concept and successful commercialization. WFC's goal is that the $\mathrm{IN}^{2}$ program will help build the necessary momentum for participating enterprises to traverse the valleys of death with greater efficiency.

To summarize, the $\mathrm{IN}^{2}$ model adds a number of key elements into a "commercialization ecosystem" that traditional accelerators have not included to date, as summarized in Table 3. 
Table 3. Key Attributes of Accelerators and the Wells Fargo Innovation Incubator

\begin{tabular}{|lll|}
\hline Attribute/Approach & Accelerator & $\begin{array}{l}\text { Wells Fargo Innovation } \\
\text { Incubator }\end{array}$ \\
\hline Eligibility & Compete & Compete \\
\hline Access & $\begin{array}{l}\text { Large N (high number of } \\
\text { companies) }\end{array}$ & $\begin{array}{l}\text { Small N (small number of } \\
\text { companies) }\end{array}$ \\
\hline Financing Support Type & Equity & $\begin{array}{l}\text { Grant, plus possible } \\
\text { commercial banking, and } \\
\text { continued sales and corporate } \\
\text { funding support }\end{array}$ \\
\hline Strategic Approach & Speed & Supportive compression \\
\hline Supportive Elements & N/A & \begin{tabular}{l} 
Engineering validation \\
\hline Commercial Runway
\end{tabular} \\
\hline
\end{tabular}

While promising in structure, the $\mathrm{IN}^{2}$ model's effectiveness is still to be tested as the initially selected companies progress through their commercialization efforts. An even wider array of collaborative possibilities may be available for other investors interested in supporting the accelerated commercialization of innovative technologies as similar partnerships emerge. 


\section{Conclusions}

Traditional methods for advancing clean energy technologies from concept to commercial solutions are best known for relatively slow, linear progression through RDD\&D and were characterized by valleys of death for financing. Achieving expected returns for venture capital investors has proved challenging, particularly for hardwarecentric innovations and companies that were subject to project finance risks. Commercialization methods ranging from incubators to accelerators that offer more services to start-ups can help address these challenges.

However, it is the development of new strategic investors and partners in recent years that has opened up innovative opportunities for clean tech entrepreneurs. More importantly, novel commercialization acceleration models are emerging that involve new alliances among clean tech companies, support systems, and strategic customers. With the engagement of these new models the clean energy future looks bright. 


\section{References}

BNEF (Bloomberg New Energy Finance). 2010. Crossing the Valley of Death. New York: Bloomberg New Energy Finance.

EIA (U.S. Energy Information Administration). 2015. "How Much Energy Is Consumed in Residential and Commercial Buildings in the United States?" Last updated April 3. http://www.eia.gov/tools/faqs/faq.cfm? id=86\&t=1.

Heap, D., J. Pless, and N. Aieta. 2013. “Clean Energy Finance: Challenges and Opportunities of Early-Stage Energy Investing." NREL/PR-6A50-60882-1. Presented at National Renewable Energy Laboratory Industry Growth Forum, Golden, Colorado, December 3-4. http://www.nrel.gov/docs/fy14osti/60882-1.pdf.

Jenkins, Jesse, and Sara Mansur S. 2011. Bridging the Clean Energy valleys of death: Helping American Entrepreneurs Meet the Nation's Energy Innovation Imperative. Oakland, CA: Breakthrough Institute. http://thebreakthrough.org/archive/bridging_the_clean_energy_vall.

Malek, Kourosh, Elicia Maine, and Ian P. McCarthy. 2014. "A typology of clean technology commercialization accelerators." Journal of Engineering and Technology Management 32:26-39. http://dx.doi.org/10.1016/j.jengtecman.2013.10.006.

Murphy, Lawrence M., Ron Ondecheck, Ricardo Bracho, and John McKenna. 2014. "Clean Energy_-Bridging to Commercialization: The Key Potential Role of Large Strategic Industry Partners.” FEEM Working Paper No. 092.2014. http://dx.doi.org/10.2139/ssrn.2520343.

NREL (National Renewable Energy Laboratory). 2015. "Commercialization Assistance Program.” Last modified July 1. http://www.nrel.gov/technologytransfer/ncap.html.

PwC. 2013. Cleantech MoneyTree Report: Q2 2013. New York: PwC.

Rai, Varun, Erik Funkhouser, Trevor Udwin, and David Livingston. 2015. "Venture Capital in Clean Energy Innovation Finance: Insights from the U.S. Market during 20052014." Social Science Research Network (October).

http://dx.doi.org/10.2139/ssrn.2676216.

Rosen, Raphael. 2013. "Why Venture Capital is Weak Fuel for CE Startups." Forbes, February 2. http://www.forbes.com/sites/energysource/2013/02/13/why-venture-capitalis-weak-fuel-for-clean-energy-startups/.

St. John, Jeff. 2014. "CalCharge: A Model for California Energy Storage Dominance." GreenTech Media, April 23. https://www.greentechmedia.com/articles/read/calcharge-amodel-for-california-energy-storage-dominance. 
UNEP/BNEF (United Nations Environment Programme/Bloomberg New Energy Finance). 2013. Global Trends in Renewable Energy Investment 2013. Frankfurt, Germany: Frankfurt School of Finance and Management. http://www.unep.org/pdf/GTRUNEP-FS-BNEF2.pdf. 